\title{
Classifying zones of suitability for manual drilling using textural and hydraulic parameters of shallow aquifers: a case study in northwestern Senegal
}

\author{
F. Fabio Fussi ${ }^{1} \cdot$ Letizia Fumagalli $^{1} \cdot$ Francesco Fava $^{1} \cdot$ Biagio Di Mauro $^{1}$. \\ Cheik Hamidou Kane ${ }^{2} \cdot$ Magatte Niang $^{3} \cdot$ Souleye Wade $^{3} \cdot$ Barry Hamidou $^{4}$. \\ Roberto Colombo ${ }^{1}$. Tullia Bonomi ${ }^{1}$
}

Received: 30 June 2016 / Accepted: 5 July 2017 /Published online: 14 August 2017

(C) The Author(s) 2017. This article is an open access publication

\begin{abstract}
A method is proposed that uses analysis of borehole stratigraphic logs for the characterization of shallow aquifers and for the assessment of areas suitable for manual drilling. The model is based on available borehole-log parameters: depth to hard rock, depth to water, thickness of laterite and hydraulic transmissivity of the shallow aquifer. The model is applied to a study area in northwestern Senegal. A dataset of boreholes logs has been processed using a software package (TANGAFRIC) developed during the research. After a manual procedure to assign a standard category describing the lithological characteristics, the next step is the automated extraction of different textural parameters and the estimation of hydraulic conductivity using reference values available in the literature. The hydraulic conductivity values estimated from stratigraphic data have been partially validated, by comparing them with measured values from a series of pumping tests carried out in large-diameter wells. The results show that this method is able to produce a reliable interpretation of the shallow hydrogeological context using information generally available in the region. The research contributes to improving the identification of areas where conditions are suitable for manual drilling. This is achieved by applying the described method, based on a structured and semi-quantitative approach, to classify the zones of suitability for given manual drilling
\end{abstract}

F. Fabio Fussi

fabio.fussi@usa.net

1 Department of Environmental Science, University Milano Bicocca, Piazza della Scienza 1, Milan, Italy

2 University of Thies, Thies, Senegal

3 University Cheik Anta Diop, Dakar, Senegal

4 SNAPE (Service Nationale de Points d'Eau), Conakry, Guinea techniques using data available in most African countries. Ultimately, this work will support proposed international programs aimed at promoting low-cost water supply in Africa and enhancing access to safe drinking water for the population.

Keywords Groundwater development · Unconsolidated sediments $\cdot$ Water supply $\cdot$ Drilling $\cdot$ Senegal

\section{Introduction}

Despite overall progress, 748 million people still had no access to safe drinking water in 2012, 325 million (43\%) of whom were living in Sub-Saharan Africa (WHO/UNICEF 2014). Groundwater has proven to be the most reliable resource for meeting rural water demand in Sub-Saharan Africa, and it can derive from different types of aquifers. Unconsolidated sediments cover $22 \%$ of Sub-Saharan Africa, and at least 60 million people in rural areas obtain water from this type of aquifer (MacDonald and Davies 2000).

Manual drilling refers to several drilling methods that rely on human energy to construct a borehole (i.e. a narrow hole bored in the ground using some kind of drilling tools) and complete a water supply (Danert 2015). These techniques are well established in certain countries, e.g. Bangladesh, Bolivia, India, Kenya, Niger, Nigeria and Madagascar. In recent years, however, there has been an increased interest in promoting manual drilling in regions where this technique is rarely applied even though it could improve access to clean water. UNICEF (United Nations International Children's Emergency Fund) has been involved in this process in Africa since 2004 (Gaya 2004). Other organizations have gathered experience in pilot projects to promote manual drilling in different regions (e.g. Forsyth et al. 2010); these 
techniques are now becoming increasingly relevant in several countries (Danert 2009, 2015).

Although different techniques for manual drilling are available (Carter 2005; Danert 2015), they can be applied only where shallow geological layers are relatively soft (i.e. it is possible to drill using manually powered tools) and the water table is not too deep (i.e. that exploitable water strikes occur within a depth range achievable with manual drilling techniques; $50 \mathrm{~m}$ can be a realistic value for the maximum depth commonly reached by hand-drilled wells, although there are examples that reach up to $100 \mathrm{~m}$ ). Therefore, the promotion of manual drilling to improve water supply requires a preliminary identification of those zones with suitable hydrogeological conditions. Such an approach was initially tested in Chad using the water points' database of the national water authorities (Direction de l'Hydraulique) and a simple procedure of visual interpretation of the variations in static water level and the distribution of geological units (Gaya et al. 2005). The Chad study was used for an intense program of promotion of manual drilling by UNICEF and the national water authority, which resulted in thousands of new excellent hand-drilled wells in the country (Danert 2015), with a network of private contractors trained in high-quality construction techniques. Following the Chad experience, UNICEF produced maps of suitable zones at country level within Africa, applying a schematic model with some modifications in 12 countries between 2008 and 2010 (Fussi 2011; Fussi et al. 2013). Suitable zones for manual drilling were derived from the analysis of three main parameters: geological suitability (depending on the thickness and permeability of shallow layers), water depth suitability (depending on static water level in the first aquifer) and morphological suitability (based on the existence of landforms that facilitate the accumulation of unconsolidated sediments or erosion). This method was based on the analysis of water point databases, geological maps and the Shuttle Radar Topography Mission (SRTM) digital elevation model, integrated with qualitative experience of local hydrogeologists. Major relevance is given to the national water point database, i.e. the centralized archive of water point data generally held by the national water authority in each country. This source of information contains a large amount of data but generally presents several problems in their quality (not up-to-date, duplicated records, incorrect and incomplete information). These data were analysed only through a simple qualitative visual interpretation (a robust and quantitative procedure of elaboration was not proposed). A similar approach derived from a cross analysis of shallow geology (obtained from the simplification of geological maps) and depth to water (assigning an estimated range of this parameter to the category of landforms obtained by processing the SRTM digital elevation model) was used in Madagascar (Salama 2008). A different method was applied in Tigray, northern Ethiopia (Huisman Foundation 2014). This approach is based on direct field survey (observation of landscape characteristics, soil type and water level in hand-dug wells) and discussion with local experts.

A method to investigate one of the relevant aspects to consider for the feasibility of manual drilling (water depth) was proposed in Niger (Thomas et al. 2012). It is based on a multivariate statistical procedure for the estimation of water depth through an indirect set of information (remote sensing, terrain modelling, thematic maps). Even though it does not propose a complete method for the identification of suitable zones, this research does suggest a method to characterize the shallow hydrogeological context.

Regardless of the sources of information, all these methods to determine the suitability of an area for manual drilling take the same criteria into consideration: properties of the shallow geological layers and water-level depth. The study in Tigray had a detailed field survey and therefore is applicable only for relatively small study areas; however, the other methods all have similar critical aspects:

- They depend on existing information (like thematic maps, qualitative experience of local experts) that is often incomplete and does not homogeneously cover the whole country, leading to unreliable interpretation where this information is limited.

- They can support regional- and national-scale analysis, but they are not applicable at local level, given the coarse scale of the mapping products and low spatial density of information.

- They are largely based on qualitative perception and assessment of experts, without a structured data analysis procedure. This makes it difficult to replicate the study and compare the results in different areas.

The main objective of this study is to propose a new method to identify suitable zones for manual drilling, based on a semi-quantitative estimation of hydrogeological data and a robust process of data analysis. Specifically, the proposed approach aims at improving existing methods by:

- A more structured and quantitative procedure to analyse existing geological datasets, especially those coming from national water point databases and borehole stratigraphic logs.

- A systematic approach for borehole data processing, with inclusion of information available only in hard copy and a limited field survey for a general validation. Integrating this information makes it easier to increase the level of detail of the mapping products, compared with previous maps at regional or country level.

- A more objective, systematic and replicable workflow. 


\section{Materials and methods}

\section{Description of the study area}

The study area is the Louga region in north-western Senegal, between $14^{\circ} 70^{\prime}$ and $16^{\circ} 10^{\prime}$ north and $14^{\circ} 27^{\prime}$ to $16^{\circ} 50^{\prime}$ west (Fig. 1), and covers $24,874 \mathrm{~km}^{2}$. It was selected in order to target zones with different shallow hydrogeological features and different suitability for manual drilling, as obtained from the existing study in the framework of the UNICEF program (Kane et al. 2013).

The total population of the study area is 880,482 inhabitants (more than 500,000 inhabitants in rural areas), with 57\% having access to safe drinking water and $17 \%$ having adequate sanitation (PEPAM 2015). Climatic conditions are characteristic of the Sahelian regime, with rainfall approximately 350 $500 \mathrm{~mm} /$ year (with a decreasing trend moving to the north), concentrated between June and October. Along the coastal area, there is the effect of a humid wind brought by the Azores Anticyclone. Morphology is mainly flat, with limited undulation formed by sandy dunes. From the geological point of view, the study area is situated in the Tertiary SenegaloMauritanian sedimentary basin, constituted by interbedded layers of limestone, sandstone, marl and clay, and elongated in the $\mathrm{N}-\mathrm{S}$ direction for $1,400 \mathrm{~km}$ from Mauritania to Guinea Bissau. This sedimentary basement is covered by sands or sandy clay. Moving eastward, there are different sandy formations (with an increase in the presence of clay): the coastal dunes, the Ogolian red dunes, and the Continental terminal.

\section{Source of data}

The method is based mainly on a detailed analysis of previously existing data, most of it acquired free of charge. Direct field data collection is limited and principally focused to validate the interpretation. The main sources of data are thematic maps and hydrogeological information obtained from the national database of water points of Senegal. Geology, soils, morphopedology and land-cover datasets have been obtained from 1:500,000 maps published for the national plan for land-use and development (The Remote Sensing Institute South Dakota State University 1986). Water points data were obtained from the national inventory held by DGPRE (Direction de la Gestion et de Planification des Ressources en Eaux) in Senegal; this database is part of the geographic information system of water resources (République du Sénégal 2000) from SGPRE (Service de Gestion et de Planification des Ressources en Eau), and it is managed with the software PROGRES (ANTEA/BURGEAP 2007). Three categories of data have been obtained from the water point database:

1. General inventory of water points $(1,277$ records in the study area, including deep boreholes and hand-dug wells). They cover all the study area, although there is a much higher concentration on the western side. From this dataset, it was possible to obtain the position and total depth of the boreholes/wells and the depth to static water level.

2. Inventory of piezometers (45 records in the study area, almost completely concentrated in the coastal region, not more than $50 \mathrm{~km}$ away from the sea). The piezometers have the same information as the general inventory of water points, plus the description of the main aquifer and a few time-series of static water level observations.

3. Stratigraphic logs of boreholes (131 in the study area, mainly concentrated on the western side). These logs have the same information as the general inventory, plus the lithological description and position of different layers found during the drilling. No stratigraphic logs are available for hand-dug wells.
Fig. 1 Location of the study area, the Louga region (delineated by a red line) in Senegal

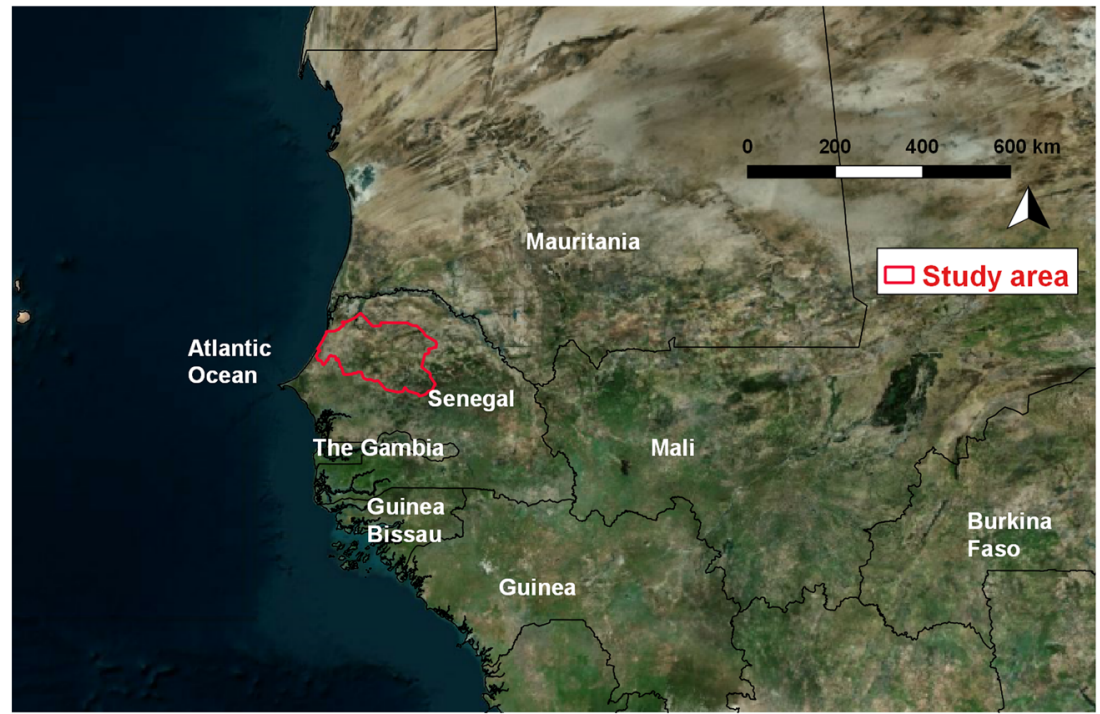


Since the information of elevation stored in the national water point database proved to be unreliable, it was neglected, and the elevation was obtained from publicly available digital terrain models (Aster Global Digital Elevation Model v.2, 30$\mathrm{m}$ resolution). The national water point database stores information concerning mechanized boreholes, but limited attention is paid to large-diameter shallow wells. Furthermore, stratigraphic logs are generally not detailed for shallow layers, and data about hydraulic parameters refer to deep, fractured aquifers. Concerning the use of static water-level data to estimate the depth to the shallow water table, two aspects must be carefully considered:

1. Most of the data (from boreholes and piezometers) refer to a deep fractured aquifer, whose piezometric level can differ from the shallow water table in the case of confining layers between the two aquifers (as in the central-eastern side of the study area); here, the estimation of the depth of water that can be exploited using manual drilling is uncertain.

2. Static water level in the national water point inventory was measured in different years and seasonal conditions. The difference in water level could be the consequence of temporal changes and may not be related to the piezometric gradient of the water table. However, the extremely limited information available from the temporal series of static water level (data from four piezometers in the coastal zone, whose water level was measured in October 2011 and August 2014) shows a change over time smaller than $30 \mathrm{~cm}$.

\section{Classification of zones of suitability for manual drilling}

The methodology proposed in this report to classify suitable zones for manual drilling is based on a structured and semiquantitative analysis of available borehole log data. The method can be applied in three steps: (1) assessment of feasibility, (2) estimation of potential for exploitation, (3) final classification of suitability.

\section{Assessment of feasibility}

Assessing the feasibility of manual drilling in a specific location means evaluating whether the existing hydrogeological conditions allow the completion of a hand-drilled well (with the different techniques available). This assessment was carried out by analysing two main parameters extracted from borehole logs: the presence of hard layers and the depth to the water level. The locations of hard stratigraphic layers can be derived from the locations of hard rock (in this case the layers generally represent the maximum possible depth of manual drilling in that area) or compact laterite (the layers are intercalated between unconsolidated sediments, and they can be broken with special manual drilling techniques, if they have limited thickness, and drilling can continue deeper). Based on these considerations, the procedures to assess feasibility for manual drilling can be schematized as a sequence of three conditions, evaluated through Boolean operators (yes/ no), and schematized in Fig. 2:

- Condition 1: depth to hard rock. In the assessment of feasibility for manual drilling, hard rock is considered a solid layer which has significant hardness and compactness, and which is generally impossible to perforate using drilling tools operated by human energy (drilled without power obtained from mechanized machine). In terms of the geological process, such hard rock layers could correspond to the bottom of the weathered and unconsolidated material covering the fresh compact rock, or the lower limit of unconsolidated layers derived from the depositional process on top of the basement rock. The presence of hard rock at the ground surface, or shallower than $10 \mathrm{~m}$, means that manual drilling is not recommendable; even in the case of a water table close to the ground surface, a water-column depth of maximum $10 \mathrm{~m}$ leads to unreliable water supply from the wells, especially during dry periods (when the water table becomes deeper). Therefore, in this situation, a complete and successful hand-drilled well is considered not feasible.

- Condition 2: depth to water. This parameter refers to the minimum depth of water strikes that can be attained in hand-drilled wells. In the case of the unconfined water

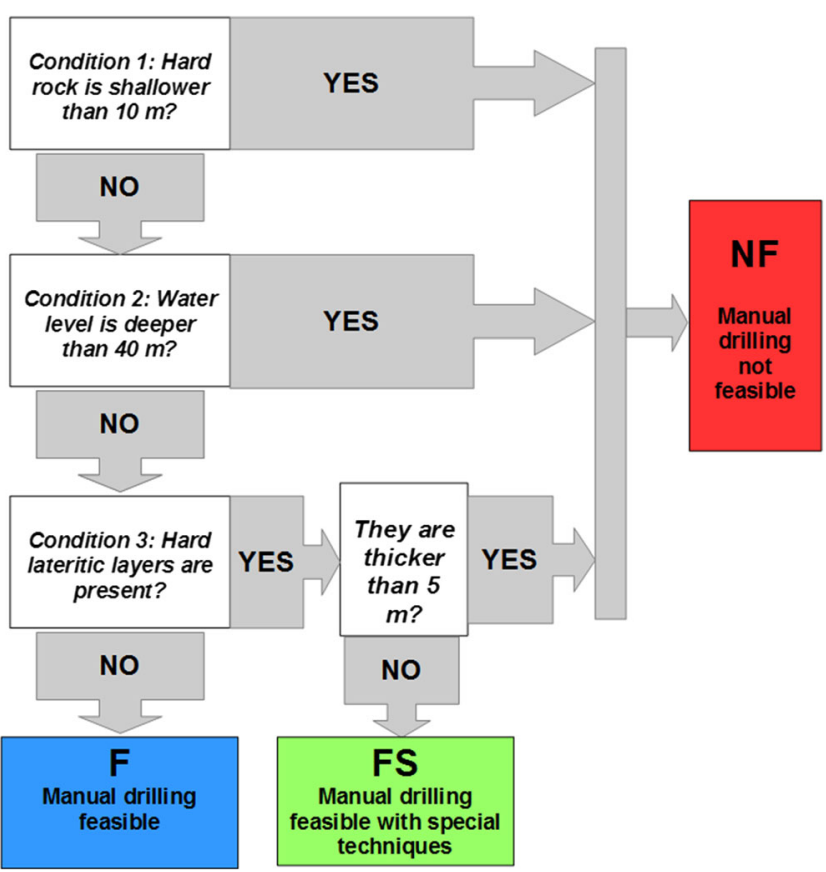

Fig. 2 Schematization of the procedure to assess feasibility of manual drilling. $F$ feasible, $F S$ feasible with special techniques, $N F$ not feasible 
Table 1 Classes of feasibility for manual drilling

\begin{tabular}{ll}
\hline Class of feasibility & Description \\
\hline Not feasible (NF) & $\begin{array}{l}\text { Not feasible because of the presence of shallow hard rock, large depth to water, and a thick lateritic hard layer } \\
\text { Manual drilling can be successfully done in this hydrogeological context }\end{array}$ \\
$\begin{array}{l}\text { Feasible (F) } \\
\text { Feasible with special techniques (FS) }\end{array}$ & $\begin{array}{c}\text { Manual drilling can be done, but the presence of hard intercalated layers necessitates the use of special } \\
\text { techniques at a certain depth (e.g. percussion) to break it, together with other common methods to drill } \\
\text { in unconsolidated sediments }\end{array}$ \\
\hline
\end{tabular}

table, the piezometric level corresponds to the first water strike, while in the case of confined aquifers, there are different levels. As mentioned in section 'Introduction', a reference value of $50 \mathrm{~m}$ was assumed as the maximum depth commonly achievable using manual drilling; this seems to be consistent with previous experience in Senegal. Given this assumption, and considering that a few metres of water column is needed to ensure a positive result, the limit of $40 \mathrm{~m}$ as a maximum water-level depth was kept as a threshold for the feasibility of manual drilling.

- Condition 3: presence of hard laterite. One common weathering product in West African soils is laterite, which is rich in aluminium and is sometimes present in very hard layers and in some other situations as a reddish, clay-rich, unconsolidated material. Hard lateritic crusts can be perforated if their thickness is limited, but special techniques (e.g. percussion) are required. Based on direct experience of manual drilling experts, perforation is probably possible for a hard lateritic crust thinner than $5 \mathrm{~m}$, while if the layers are thicker, manual drilling is considered not possible.

With this procedure, three classes of feasibility can be distinguished (Table 1): not feasible (NF), feasible (F) and feasible with special techniques (FS).

\section{Classification of the potential for exploitation}

After having identified where manual drilling is feasible (i.e. classes $\mathrm{F}$ and FS, with the option of special techniques required), the second step is the classification of the potential for exploitation in these zones. This classification can give an indication of the expected yield, availability of water during the dry season (because of seasonal fluctuation of the water level), the type of pump that can be installed and the size of the population served. The potential yield of the well is related to hydrogeological factors (i.e. the geometry and hydraulic characteristics of the target aquifer) and engineering aspects (quality of construction and performance of pumping system). In the proposed methodology, the hydrogeological aspects have been classified by extracting two parameters from the analysis of borehole logs with the procedure described in section 'Data processing and interpretation: thickness and hydraulic conductivity $(K)$ of saturated layer. The potential for exploitation with manual drilling is related to the hydraulic transmissivity in the exploitable interval $\left(T_{\mathrm{ex}}\right)$, which itself is calculated as shown in Eq. (1)

$T_{\mathrm{ex}}=K_{\mathrm{ex}} \times H_{\mathrm{ex}}$

where $T_{\text {ex }}$ is the hydraulic transmissivity $\left(\mathrm{m}^{2} / \mathrm{s}\right)$ of the exploitable layer by manual drilling (this means up to $50 \mathrm{~m}$ deep). $H_{\text {ex }}$ is total thickness (m) of the saturated exploitable layers, corresponding to the difference between static water level and $50 \mathrm{~m}$, if the upper limit of hard-rock-layer depth is $>50 \mathrm{~m}$ or the difference between static water level and the upper limit of the hard-rock layers if $<50 \mathrm{~m}$. $K_{\mathrm{ex}}$ is average hydraulic conductivity $(\mathrm{m} / \mathrm{s})$ in the saturated exploitable layer.

The potential for exploitation is considered in relation to the performance of different pumping systems available for hand-drilled wells (Table 2). Five classes of potential for exploitation are defined (Table 3). This generic approach can be applied to different regions although threshold values of $T_{\mathrm{ex}}$ are related to site-specific conditions (e.g. local characteristics of aquifers, depth of water table, seasonal fluctuations).

\section{Assigning the final class of suitability}

The final class of suitability derives from the combination of feasibility and potential for exploitation. With this method, 11 possible combinations (Table 4) are defined, with three classes of suitability: not suitable, suitable with poor results, suitable.

\section{Data processing and interpretation}

Borehole-log data were processed with the software TANGAFRIC (Fussi et al. 2014), specifically designed for this purpose during this research. Four steps were followed:

1. Standardization and identification of common categories (on the basis of the most common stratigraphic terms in the datasets from Guinea and Senegal).

2. Assignment of standard categories to the description of each layer of the stratigraphic logs by means of manual codification by two local hydrogeologists, adapting the procedures used in the software TANGRAM at the University Milano Bicocca, Italy (Bonomi 2009; Bonomi et al. 2014).

3. Extraction of textural composition of layers from the interpretation of the codes corresponding to the main texture 
Table 2 Types of pumps usually installed on hand-drilled wells and their expected yield

Type of pump Description and usage

Hand pump The most common pumping system for hand-drilled wells. Although the aquifer could be more productive, the expected yield from hand-operated pumps is approximately $0.2 \mathrm{~L} / \mathrm{s}$, with a maximum limit of $0.4 \mathrm{~L} / \mathrm{s}$ in optimal conditions. They are suitable for the whole range of static water-level depth considered as feasible for manual drilling (maximum depth of static water level $=40 \mathrm{~m}$ ) and they can provide water for groups of approximately 250 users for their domestic needs

Solar pump Solar-powered pumps can be installed in highly productive hand-drilled wells. They can supply water for a larger community (and eventually connect to small water distribution systems). Their yield depends on the power generated by solar panels (whose extension and power production can vary considerably); as a reference value, $1 \mathrm{~L} / \mathrm{s}$ is considered as a reasonable yield achievable with a solar pump in a productive aquifer, providing water to 1,000 users

Rope pump A rope pump consists of a loose hanging rope that is lowered into a well and drawn up through a pipe that reaches the water. On the rope, round disks or knots matching the diameter of the pipe are attached which pull the water to the surface. These pumps are suitable and cheap systems to collect water from hand-drilled wells in the case of small communities (approximately 50 users). They have a low yield $(0.1 \mathrm{~L} / \mathrm{s}$ as reference value), and they can be installed only where the static water level is not deeper than $15 \mathrm{~m}$

component, secondary texture component, and texture adjective.

4. Classification of the possible textural categories allowed in the coding process in five classes (Table 5): three classes discriminated on the basis of grain size (coarse, medium and fine) for unconsolidated sediments, and two other classes for hard layers (hard rock and hard laterite). Textural classification of sediments is derived from qualitative descriptions by drillers. However, a possible indication of the dimensions of particles for each category can be obtained from literature (e.g. Fetter 1994).

The stratigraphic data were processed, and the percentage of each texture class (using a weighted average procedure) was extracted for a sequence of intervals with a regular step. Table 6 shows an example of a log with "sand" between depths 0 and $4 \mathrm{~m}$ and "sandy clay" between depths 4 and $10 \mathrm{~m}$.
Hydraulic conductivity $(K)$ depends on texture (in the case of unconsolidated materials) or characteristics of fracturing (in the case of rocks). Ideally, the hydraulic conductivity of geological layers must be defined through direct measurements on site-specific samples (in the laboratory), or in situ measurements (e.g. pumping test). When this information is not available, $K$ can be estimated from a hydrogeological knowledge of the region and published values of $K$ measured in similar contexts for the same type of layers, defining a relation between the texture of sediments and $K$ of superficial deposits (MacDonald et al. 2012). The available local information on shallow aquifers was limited. The data on existing pumping test found in the study area carried out in boreholes from the national database of DGPRE and SNAPE (Service Nationale de Points d'Eau, Guinée) indicate $K$ values referred to deep fractured hard rock, while none of the pumping tests provide hydraulic parameters referred to unconsolidated shallow layers. Also, there are strong limitations on the availability of hydrogeological studies.

Table 3 Classes of potential for exploitation

\begin{tabular}{ll}
\hline Class of potential & Description \\
\hline NP: potential null & $\begin{array}{r}\text { Physically, manual drilling can be done, but the well will be dry, since the water level is deeper than the hard-rock } \\
\text { depth (i.e. the maximum depth achievable by manual drilling). Therefore, the porous aquifer is completely dry ( } H_{\text {ex }}=0 \text { ) }\end{array}$ \\
LP: low potential & $\begin{array}{r}\text { Hand-drilled wells can be equipped with hand pumps, but expected yield is low (less than 0.2 L/s). After intense } \\
\text { pumping, or in the case of a decreasing water level, the well is likely to become dry }\end{array}$ \\
MP: moderate potential & $\begin{array}{r}\text { Hand-drilled wells can be equipped with hand pumps and provide a reliable water supply; pumping cannot be } \\
\text { continuous for a long time (for example, for } 2 \text { h or more, as is frequent during peak hours for water collection } \\
\text { in rural areas in Africa). Not suitable for intense utilization by large groups (i.e. less than 100 users) }\end{array}$ \\
GP: good potential & $\begin{array}{r}\text { Hand-drilled wells can provide a continuous water supply, with adequate yield using hand pumps. Suitable for } \\
\text { medium-sized communities (approximately } 250 \text { users, which is often a guideline value of maximum users for hand } \\
\text { pumps in water supply programs) }\end{array}$ \\
EP: excellent potential & $\begin{array}{r}\text { Hand-drilled wells can provide an excellent yield (higher than 0.5 L/s). The well can supply water for a continuous } \\
\text { utilization of hand pumps and can sometimes be equipped with solar pumps (providing water to a larger population) }\end{array}$ \\
\hline
\end{tabular}


Table 4 Final classification of suitability for manual drilling

\begin{tabular}{clll}
\hline $\begin{array}{c}\text { Feasibility } \\
\text { Not feasible } \\
\text { NF } \\
\text { Feasible }\end{array}$ & $\begin{array}{l}\text { Potential for } \\
\text { exploitation }\end{array}$ & Combination & Class of suitability \\
F & NP & NF & Not suitable \\
& LP & F-NP & Not suitable \\
& MP & F-MP & Suitable with poor results \\
& GP & F-GP & Suitable \\
& EP & F-EP & Suitable \\
Feasible with & Special techniques & \\
FS & NP & FS-NP & Not suitable \\
& LP & FS-LP & Suitable with poor results \\
& MP & FS-MP & Suitable \\
& GP & FS-GP & Suitable \\
& EP & FS-EP & Suitable \\
\hline
\end{tabular}

$N P$ potential null; $L P$ low potential; $M P$ moderate potential; $G P$ good potential; $E P$ excellent potential; $F$ feasible; $F S$ feasible with special techniques; $N F$ not feasible

Different methods are available to estimate hydraulic conductivity from grain size of sediments. The following $K$ values for different texture classes (as defined in Table 5) were obtained from literature (Domenico and Schwartz 1998; Fetter 1994; Freeze and Cherry 1979; Neuzil 1994; Sheperd 1989) and adopted:

$K=10^{-4} \mathrm{~m} / \mathrm{s}$ for coarse material (corresponding only to sand deposits in this region, as no gravel is present)

$K=10^{-5} \mathrm{~m} / \mathrm{s}$ for medium texture material

$K=10^{-6} \mathrm{~m} / \mathrm{s}$ for fine texture material

In the case of consolidated hard materials, $K=10^{-6} \mathrm{~m} / \mathrm{s}$ was assumed (considering the presence of unconsolidated sediments filling the empty space of the hard layer). However, when hard rock represents more than $50 \%$ of the components, the layer is assumed to be the upper limit of the basement, and manual drilling cannot be performed. With the distribution of hydraulic conductivity lognormal, the standard practice was

Table 5 Texture classes

\begin{tabular}{ll}
\hline Texture class & Categories \\
\hline Coarse texture & Sand, gravel \\
Medium texture & Marl, silt \\
Fine texture & Clay, vegetal layer, lignite, laterite, alterite \\
Hard rock & Basalt, limestone, dolerite, gabbro, granite, \\
& sandstone, quartz, schist, silex \\
Hard laterite & Lateritic crust \\
\hline
\end{tabular}

followed of calculating the weighted standard mean of values attributed to the individual lithology, both as percentages of each stratigraphic level and as components of the stratigraphic stretch analysed (Sanchez-Vila et al. 1995). In this way, the $K$ value was estimated for each interval of $2 \mathrm{~m}$, obtaining from the weighted average of $\log [K]$ of each texture class multiplied by its percentage, as shown in Eq.(2):

$$
\begin{aligned}
\log [K]_{\text {interval }}= & \log [K]_{\text {coarse }} \times \% \text { coarse } \\
& \times \% \text { medium }+\log [K]_{\text {medium }}+\log [K]_{\text {fine }} \times \% \text { fine } \\
& +\log [K]_{\text {cons. }} \times \% \text { cons. }
\end{aligned}
$$

where $K_{\text {interval }}$ indicates the estimated hydraulic conductivity of the interval composed by a mix of different textural classes. At this point, it is possible to estimate the transmissivity in the exploitable layer ( $T_{\text {ex }}$, multiplying the average $K$ in the saturated layer $\left(K_{\mathrm{ex}}\right.$, between the static water level and the upper limit of basement or the maximum possible depth of $50 \mathrm{~m}$ ) and its thickness $\left(H_{\mathrm{ex}}\right)$.

The output table was processed obtaining the following parameters for each borehole log: depth to hard rock, depth to water, thickness of hard lateritic layers, average estimated hydraulic conductivity and hydraulic transmissivity of exploitable layer. The meaning of "depth to rock" and "depth to water" was explained earlier. Since there is often no sharp transition from unconsolidated layers to hard rock, it was assumed that the depth to hard rock corresponds to the upper limit of layers having more than $>50 \%$ of textural component in the output table classified as hard rock, while the depth to water was approximated with the data of static water level.

\section{Validation with measured $\boldsymbol{K}$ values from field tests}

The estimated values of hydraulic parameters from the interpretation of stratigraphic logs were compared with measured parameters obtained from two field campaigns (May 2014 and March 2015) within the study area in Senegal involving pumping tests in large open wells, to obtain direct measurements of hydraulic parameters for the shallow aquifer (the expected target for manual drilling).

A total of 11 pumping tests were completed, covering different geological units. They are mainly distributed in the western and central part of the study area, as large-diameter wells are extremely rare in the eastern sector.

Since both field campaigns occurred in the late dry season, it was difficult to find wells with an adequate water column to carry out pumping tests for an extended period. Thus, the pumping phase was ideally undertaken for $1 \mathrm{~h}$, but in several cases it was interrupted after a shorter period because the water column was too small to run the pump in a safe condition. The recovery phase was monitored for $1-1.5 \mathrm{~h}$, which 
Table 6 Output table of TANGAFRIC with the distribution of texture classes for each 2-m interval

\begin{tabular}{|c|c|c|c|c|c|c|c|}
\hline \multicolumn{2}{|l|}{ Input table } & \multicolumn{6}{|c|}{ Output table after data processing } \\
\hline Depth (m) & Texture & From $(\mathrm{m})$ & To (m) & Coarse $(\%)$ & Medium (\%) & Fine $(\%)$ & Hard $(\%)$ \\
\hline \multirow[t]{2}{*}{ From 0 to 4} & \multirow[t]{2}{*}{ Sand } & 0 & 2 & 100 & 0 & 0 & 0 \\
\hline & & 2 & 4 & 100 & 0 & 0 & 0 \\
\hline \multirow[t]{3}{*}{ From 4 to 10} & \multirow[t]{3}{*}{ Sandy clay } & 4 & 6 & 30 & 0 & 70 & 0 \\
\hline & & 6 & 8 & 30 & 0 & 70 & 0 \\
\hline & & 8 & 10 & 30 & 0 & 70 & 0 \\
\hline
\end{tabular}

provided the most relevant information for the estimation of hydraulic parameters.

Since the effect of storage capacity in large diameter wells is not negligible during the pumping phase, the recovery data are a better diagnostic of aquifer parameters than the drawdown, particularly for short periods of pumping (Barker and Herbert 1989). The methods to interpret recovery data based on the assumption of equilibrium between drawdown in the well and depression in the water table (e.g. Papadopulos and Cooper 1967; Herbert and Kitching 1981; Barker and Herbert 1989; Herbert et al. 1992) were not considered suitable. Observing the linear shape of the drawdown curve (Fig. 3) and the ratio between the volume of the well that was emptied during the test and the total volume of water extracted, a "slug test" approach for the interpretation was selected. Slug tests are good for the estimation of aquifer properties in hand-dug wells because they are commonly used in low-permeability environments, take into consideration the storage of water in the well, are easy to conduct in the field and are versatile (Mace 1999). They consider the conditions of an instantaneous water removal from the well and no contribution of water from the aquifer during the pumping phase.

Amongst the different methods proposed (e.g. Hvorslev 1951; Cooper et al. 1967; Bouwer and Rice 1976; Rupp et al. 2001; Uribe et al. 2014), Bouwer and Rice's methods (and modifications by Rupp et al. 2001) seemed the most

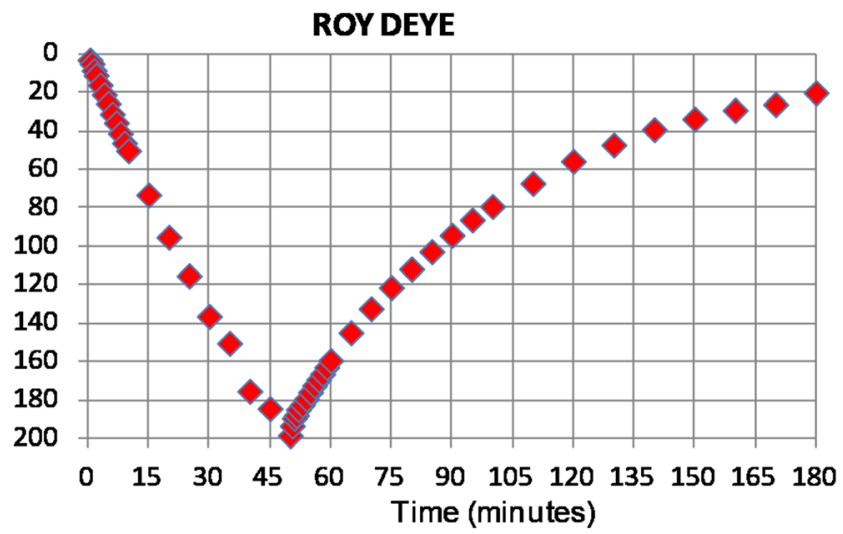

Fig. 3 Example of a drawdown and recovery curve for a pumping test executed at Roy Deye (Louga region, Senegal) suitable for the interpretation, given the geometry of the system and the development of the test. In fact, this method was designed for the interpretation of slug tests in fully or partially penetrating wells, tapping unconfined aquifers.

$K$ was estimated using Bouwer and Rice's original method (Bouwer and Rice 1976) as well as the modified equation for $\ln (\mathrm{Re} / \mathrm{Rw})$ proposed by Rupp et al. (2001) for soil classes Sa1 (Sand) and Lsal (Loamy sand) to take into account the influence of unsaturated hydraulic conductivity. Rw is the radius of the well, and Re is the effective radius over which the depression of static water level is dissipated (in Rupp's method, this parameter depends on soil texture). The following assumptions were considered (Fig. 4):

1. Condition similar to fully penetrating wells $(D=L)$. Considering that there is generally a concrete slab at the bottom of improved large-diameter wells in Senegal, water flow is therefore only horizontal and the base of the well can be considered an impermeable layer.

2. The well is fully screened, therefore filtration occurs along the whole well surface between the water table and the

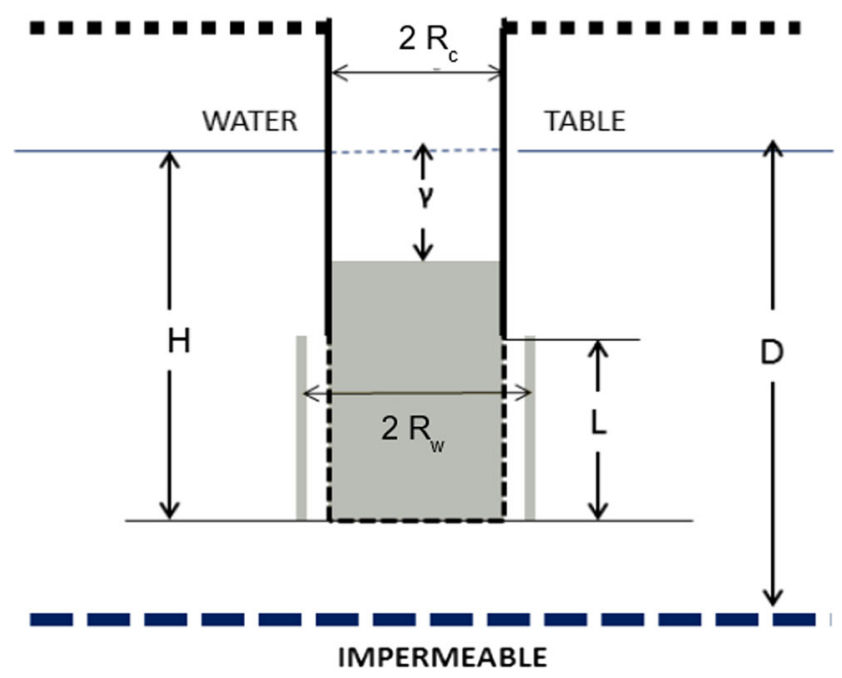

Fig. 4 Geometry and symbols for partially penetrated wells in an unconfined aquifer. From Bouwer and Rice (1976). $H=$ distance between water table and bottom of the well, $D=$ distance between water table and bottom of the aquifer, $L=$ length of screened section of the well, $R w=$ radius of the well, $R c=$ internal radius of concrete rings 
bottom of the well $(H=L)$. Although the screened section of the well (perforated concrete rings) is smaller, the presence of gravel packing up to the water table facilitates filtration even from the shallower part of the aquifer.

\section{Results and discussion}

\section{Comparison of $K$ values obtained from analysis of stratigraphic logs and pumping tests}

$K$ values obtained from the set of pumping tests executed in large-diameter wells were compared with the estimation of hydraulic conductivity obtained from the interpretation of logs from boreholes located closer than $7 \mathrm{~km}$ from the pump-tested wells. This threshold distance was selected by calculating the minimum distance required to have at least two stratigraphic $\operatorname{logs}$ at an acceptable distance from the wells (i.e. a distance where the stratigraphic information of the borehole logs can be considered reasonably valid to represent the characteristics of shallow geological layers at the well's position). The radius of $7 \mathrm{~km}$ can lead to a discrepancy in geological conditions between the open well and surrounding stratigraphic logs, especially in the presence of lateral variations (generally limited in the study area) and undulated topography. However, the low density of borehole logs (i.e. the large distance between stratigraphic data) made it difficult to assume a smaller threshold value and the researchers were obliged to accept this source of error in the comparison of $K$ values. The interpretation considered the texture of those geological layers at the same depth as the saturated interval in the well. As observed in Table 7, the mean and median of the difference in the estimation of $K$ obtained through the interpretation of pumping tests (direct measurement in the field) and processing of borehole $\operatorname{logs}$ is limited. This difference has been estimated for only seven pumping tests (out of the 11 that were executed), as some of the tests gave results considered not reliable because of the limited water column in the wells and difficulty in properly measuring the change in water level.

The results providing the best fitting with $K$ value obtained from stratigraphic logs (giving the lowest mean and median value of the difference) were obtained using Rupp's method and considering sandy soil; in 5 out of 7 cases the difference in $\log K$ between the two methods is smaller than 0.5. Two points gave a higher value of difference in $K$ value; one possible justification can be the presence of variations in texture of shallow geological layers between the open well (where the pumping test was carried out) and the surrounding borehole.

Therefore, it can be considered that the $K$ estimated during the analysis of stratigraphic logs by using TANGAFRIC is reasonably consistent with the results of pumping tests, and
Table 7 Estimation of mean and median of the difference between Log $K$ obtained through interpretation of pumping tests and borehole logs ( 7 samples). $K$ expressed in $\mathrm{m} / \mathrm{s}$

\begin{tabular}{llll}
\hline Statistic & $\begin{array}{l}K \\
\text { Rupp's method } \\
\text { (assuming soil class } \\
\text { Sa1) }\end{array}$ & $\begin{array}{l}K \\
\text { Rupp's method } \\
\text { (assuming soil class } \\
\text { Lsa1) }\end{array}$ & $\begin{array}{l}K \\
\text { Original Bouwer } \\
\text { and Rice method }\end{array}$ \\
\hline Mean & 0.42 & 0.44 & 1.22 \\
Median & 0.25 & 0.28 & 0.48 \\
\hline
\end{tabular}

is possibly slightly underestimated. One also has to consider that this method (comparing $K$ values from pumping tests in large wells with the surrounding borehole logs using texture and $\mathrm{K}$ data of layers at the same depth as the static water level of the pumping test) is based on the assumption that there is no lateral modification of texture and $K$ (only vertical modification) in the area and that topography is flat; if these conditions are not taken into account, they can introduce other relevant factors that may make this comparison less correct. On the basis of geological and morphological features of the study area, it was considered reasonable to assume limited lateral variability and thus confirm the validity of the method.

\section{Characterizing the shallow aquifer and the suitability for manual drilling based on borehole-log positions}

The method for the assessment of suitability for manual drilling was applied to the study area, and the feasibility, potential for exploitation and suitability were elaborated using maps. The results of the semi-automated analysis of borehole logs (and the comparison with direct field measurements) show the distribution of the different hydrogeological parameters considered and assign the appropriate class of suitability at borehole-log positions. The distribution of the different parameters to assess suitability in the study area is discussed.

\section{Classification of feasibility for manual drilling}

Depth to hard rock In most of the study area, the bedrock (i.e. the upper limit of tertiary sedimentary rocks under the unconsolidated deposits) is deeper than $10 \mathrm{~m}$, therefore satisfying the criteria defined in the feasibility model for manual drilling (class F and class FS). In $52 \%$ of the cases, bedrock is deeper than $50 \mathrm{~m}$, therefore manual drilling can reach its maximum depth without limitation because of geological conditions. The unconsolidated shallow layer presents a small thickness in many of the boreholes concentrated in the eastern sector, although there is high variability in the same area (Fig. 5). As a consequence, there are limitations associated with the exploitable water column in hand-drilled wells. 
Depth to water This is the most important limiting factor for the implementation of manual drilling in the study area. $45 \%$ of the logs show a static water level deeper than $40 \mathrm{~m}$ (Fig. 6); therefore, in this situation, manual drilling is considered NF according to the limits defined in the proposed classification model (Fig. 2, condition 2). The average value of water depth is $35 \mathrm{~m}$, with a standard deviation of $10.3 \mathrm{~m}$. However, estimating the depth of exploitable water from information on static water level of deep boreholes can lead to an unreliable interpretation in the case of boreholes that tap confined deep aquifers. In this situation, hand-drilled wells can only reach exploitable water that is much deeper than the estimated water level, and in some cases this may be not feasible. This situation is frequent in the central and eastern sector of the study area, where the true depth of the shallow water table can be estimated from data on static water levels in large-diameter wells. Since this information is rarely registered in the national database, direct field observation is suggested.

The most critical zones are located SE of Kebemer, in the SW sector of the study area, where the depth of groundwater makes manual drilling not feasible in several locations. Further east, there are more sites where the water depth is shallower than $25 \mathrm{~m}$. However, two relevant aspects must be considered in this zone: the limitation in drilling depth because of the presence of hard rock can make it difficult to have a sufficient water column in the well. Also, the extreme scarcity of large-diameter wells can indicate the presence of confining layers and possible errors in the estimation of the depth of the shallow water table. The coastal strip has no borehole log information, but the direct observation of large-diameter wells in the field indicates that groundwater is shallow (in most of the cases not deeper than $10 \mathrm{~m}$ ).

Thickness of hard laterite Hard laterite is not frequently found in the study area (Fig. 7). Over much of the area there is generally no laterite; therefore, it does not represent a limiting factor for the implementation of manual drilling (Fig. 2, condition 3). The presence of thick hard lateritic layers can represent an obstacle to feasibility (when laterite is thicker than $5 \mathrm{~m}$ the condition is considered not feasible, class NF) only in the south-eastern side of the study area, and in some locations in the centre (around Linguere). Furthermore, in the southern part of the region there are a number of logs showing the presence of laterite with thickness less than $5 \mathrm{~m}$; in this situation, manual drilling is considered feasible, but percussion techniques are required (class F-SP).

Assessment of feasibility for manual drilling After having calculated the three key parameters (depth to hard rock, depth to water, thickness of laterite), it is now possible to assign a specific class of feasibility for each of the borehole logs (Fig. 8), following the procedure explained in Fig. 2. In the

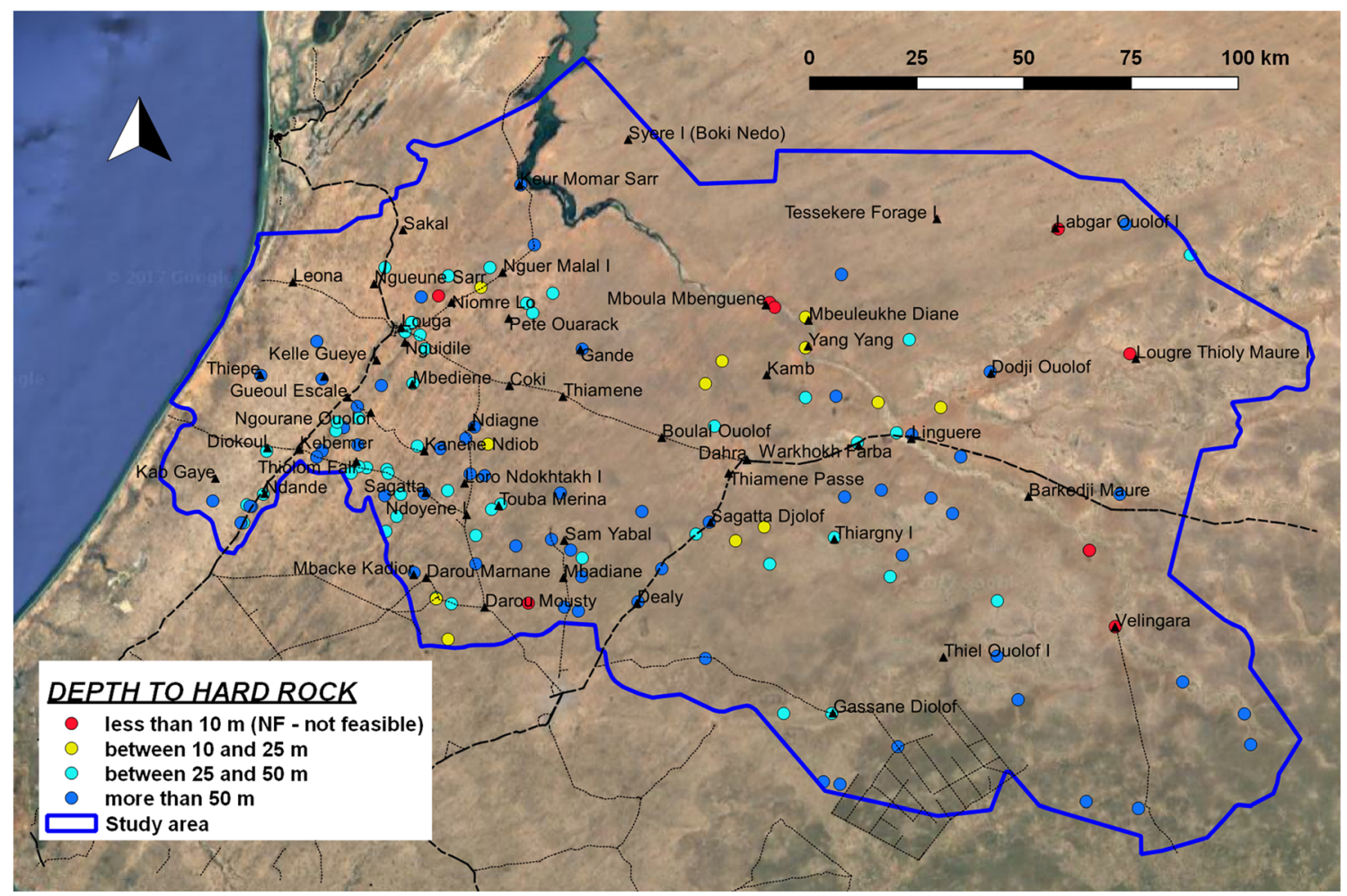

Fig. 5 Map of depth to hard rock, extracted from borehole logs 


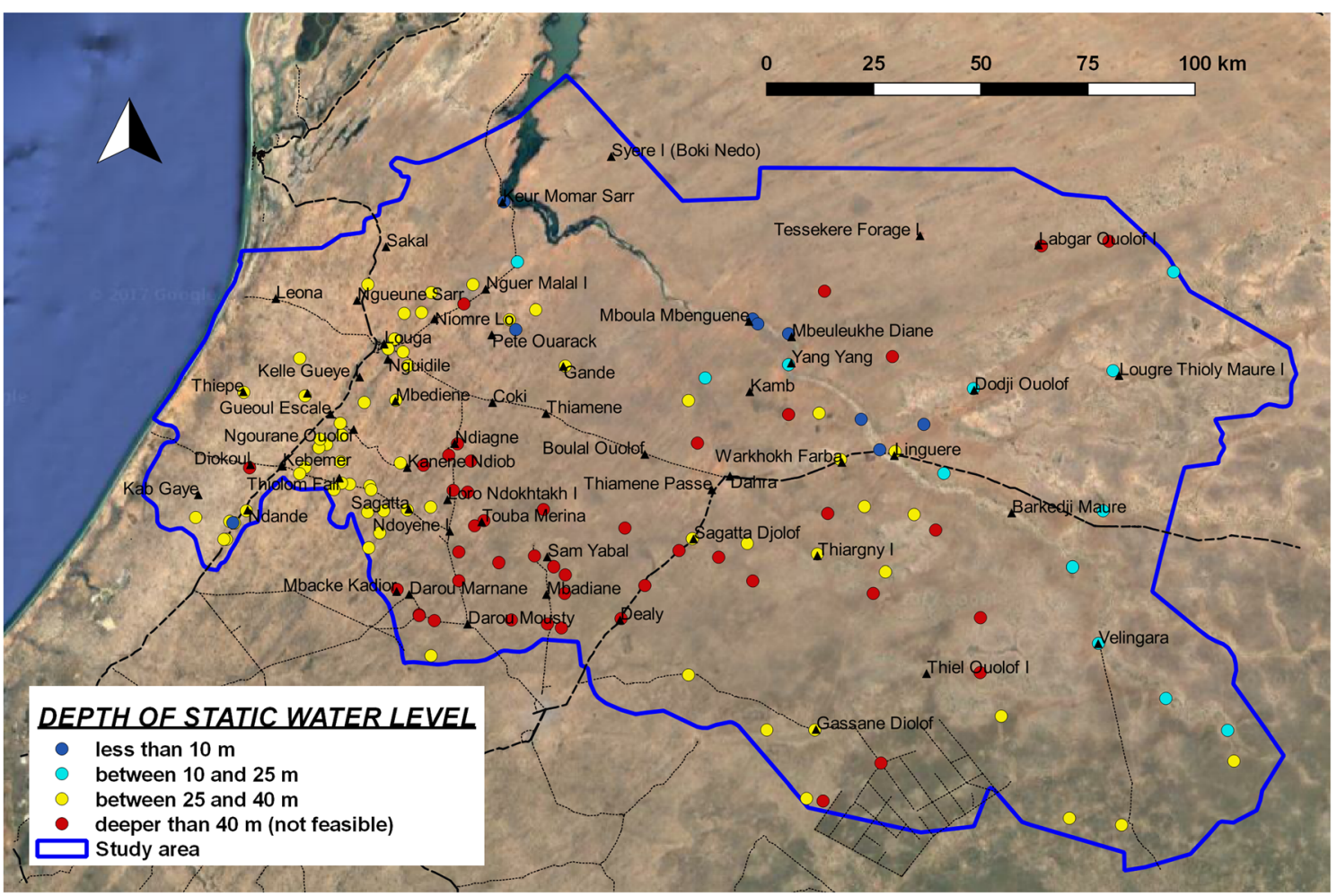

Fig. 6 Map of depth to static water level, at borehole-log positions

whole study area, $62 \%$ of the borehole logs show feasible conditions for manual drilling. Along the western coastal strip there are feasible conditions in almost the whole group of logs, while in the Ferlo Valley the trend is mixed, with a predominance of feasible conditions. Limitations in the feasibility of manual drilling are present in the southern part (mainly

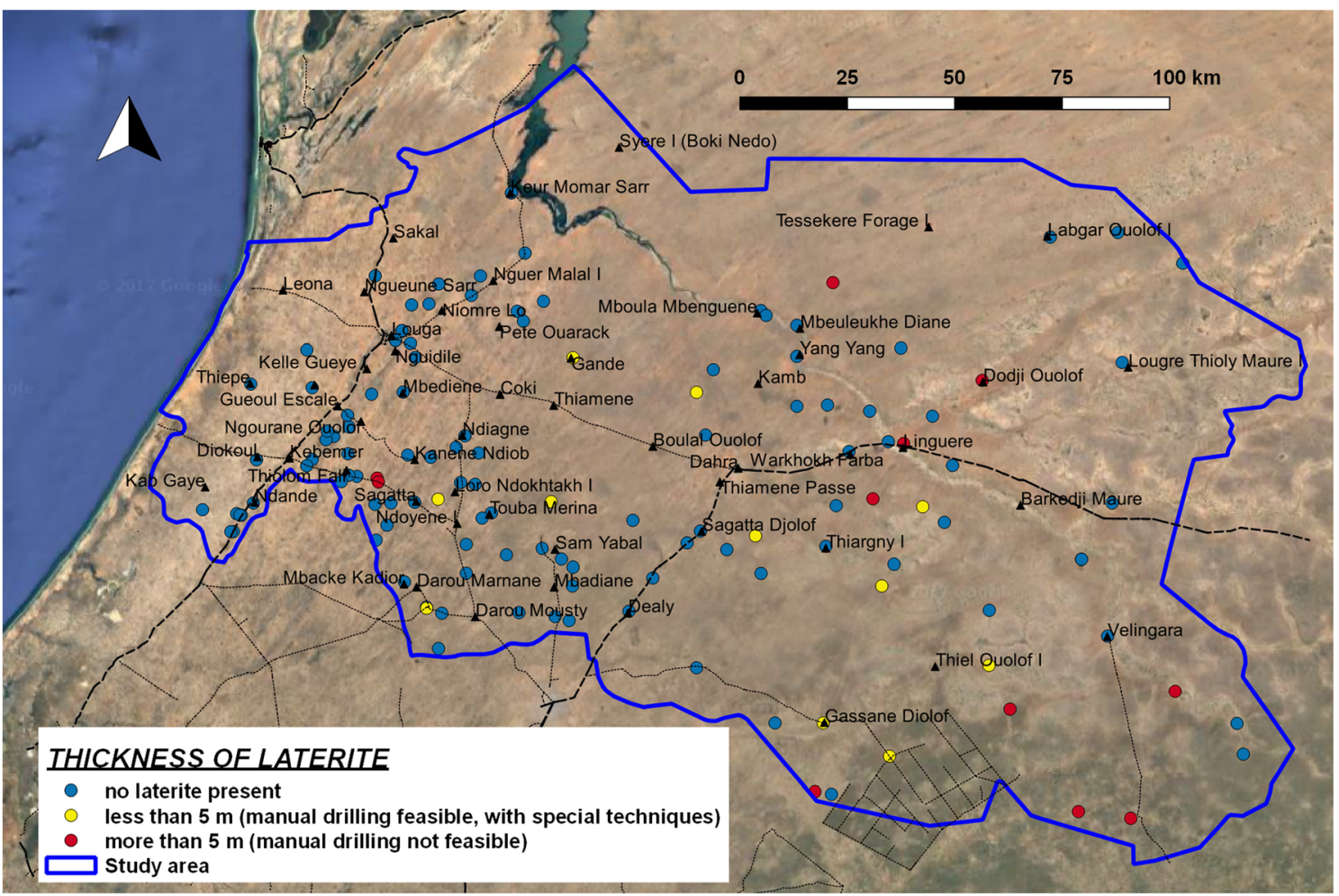

Fig. 7 Thickness of laterite layers in stratigraphic logs 


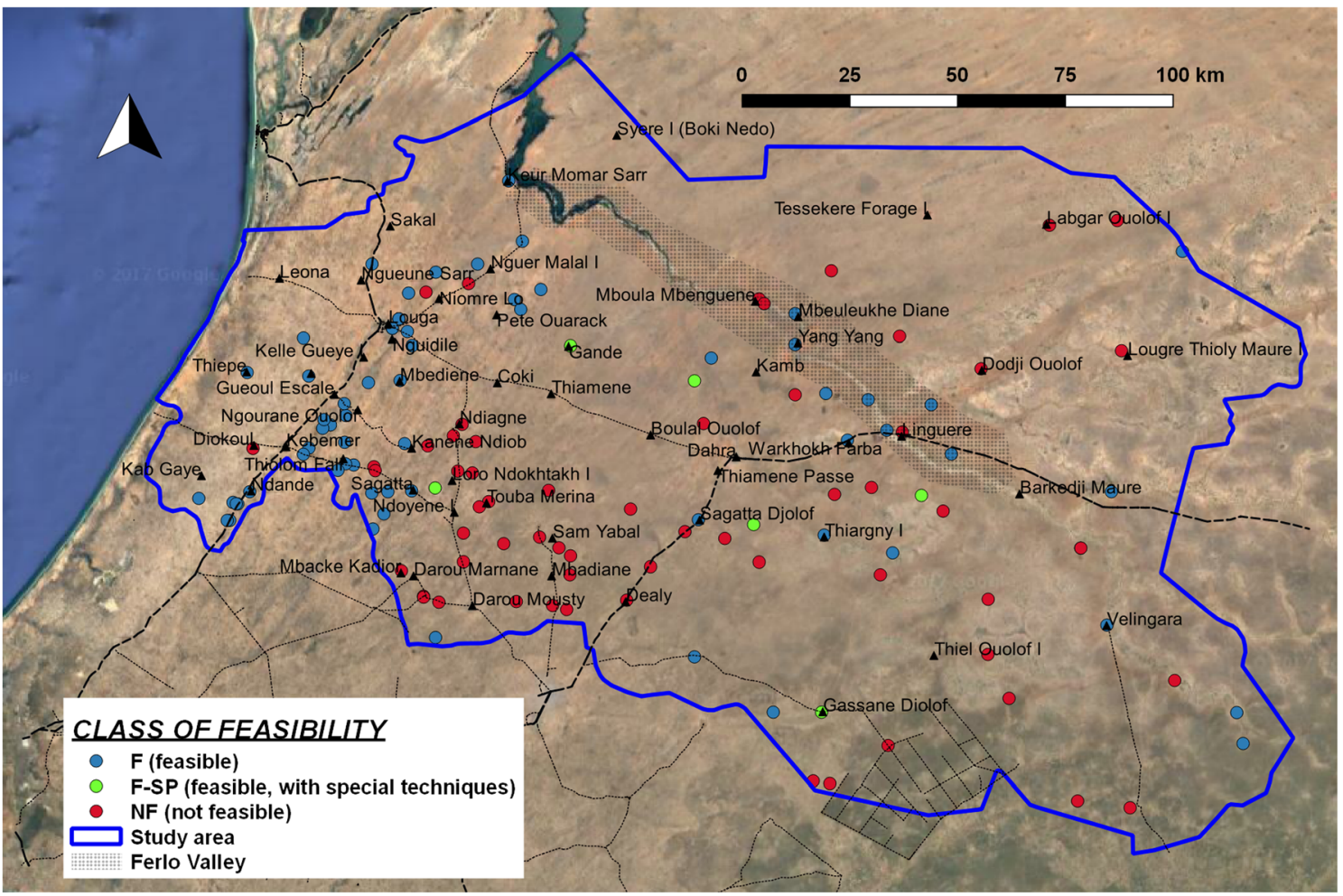

Fig. 8 Classes of feasibility for manual drilling, at borehole-log positions

because of the depth of the water level) and the NE sector (in this case, the main constraint is the limited thickness of unconsolidated layers).

It is important to underline that the presence of confined aquifers and the lack of direct data on water levels in large wells can lead to unreliable information concerning the depth of the shallow water table in the eastern part of the study area and impact the estimation of feasibility of manual drilling.

\section{Classification of suitability for manual drilling}

Hydraulic conductivity of exploitable saturated layer The estimated hydraulic conductivity of the porous shallow aquifer in the exploitable layer shows $\log (K)$ values characteristic of an intermediate texture class; considering that the medium grain size fraction is limited, the $K$ value can be attributed to a mix of sandy deposits with an important clay fraction. Average $\log (K)$ is -4.83 (corresponding to $K=1.5 \times 10^{-5} \mathrm{~m} / \mathrm{s}$ ), with a standard deviation of 0.4 . The lowest $K$ values in the exploitable layer are found SE of Kebemer and in the eastern sector of the study area. The highest values are in the coastal zone. Furthermore, a few boreholes show a high estimated $K$ value in the exploitable layer along the river valley NW of Linguere (Fig. 9). In general, hydraulic conductivity in the first metres is higher than in the deeper part of the porous aquifer: the average value of $\log$ $(K)$ between 0 and $10 \mathrm{~m}$ deep is $-4.4\left(K=4.10 \times 10^{-5} \mathrm{~m} / \mathrm{s}\right)$, while between 20 and $30 \mathrm{~m}$, it is $-5.0\left(K=1.10 \times 10^{-5} \mathrm{~m} / \mathrm{s}\right)$; in both cases standard deviation is 0.4 or 0.5 . This is related to a general trend ( $90 \%$ of the whole data set) of decreasing coarse textural fraction in the deeper layers of the shallow porous aquifer.

Thickness of exploitable saturated layer Comparing the depth to hard rock and the depth to water, the thickness of the saturated layer is obtained. For the classification of suitability for manual drilling, only the layer at maximum depth of $50 \mathrm{~m}$ is considered exploitable. Furthermore, manual drilling is not considered feasible when the exploitable layer is thinner than $10 \mathrm{~m}$. Thirty percent of the 131 boreholes do not have an exploitable saturated layer, as the water level is deeper than the depth to hard rock (or deeper than $50 \mathrm{~m}$ ), while another $29 \%$ of logs show an exploitable layer thinner than $10 \mathrm{~m}$; therefore, they are not considered to have suitable conditions for manual drilling. Forty-one percent of boreholes have sufficient thickness of saturated layer for the implementation of manual drilling, although in reality the possible effect of confining layers in the eastern part can lead to a different (and less favourable) situation (Fig. 10).

Potential for exploitation with manual drilling The threshold values of $T_{\text {ex }}$ that discriminate the different classes of potential (Table 3 ) on the basis of site-specific conditions are assigned using an approximate relation between $T_{\text {ex }}$ and expected drawdown with a hand pump (expected yield $0.2 \mathrm{~L} / \mathrm{s}$ ) and solar pump (expected yield $1 \mathrm{~L} / \mathrm{s}$ ) using Dupuit's equation 


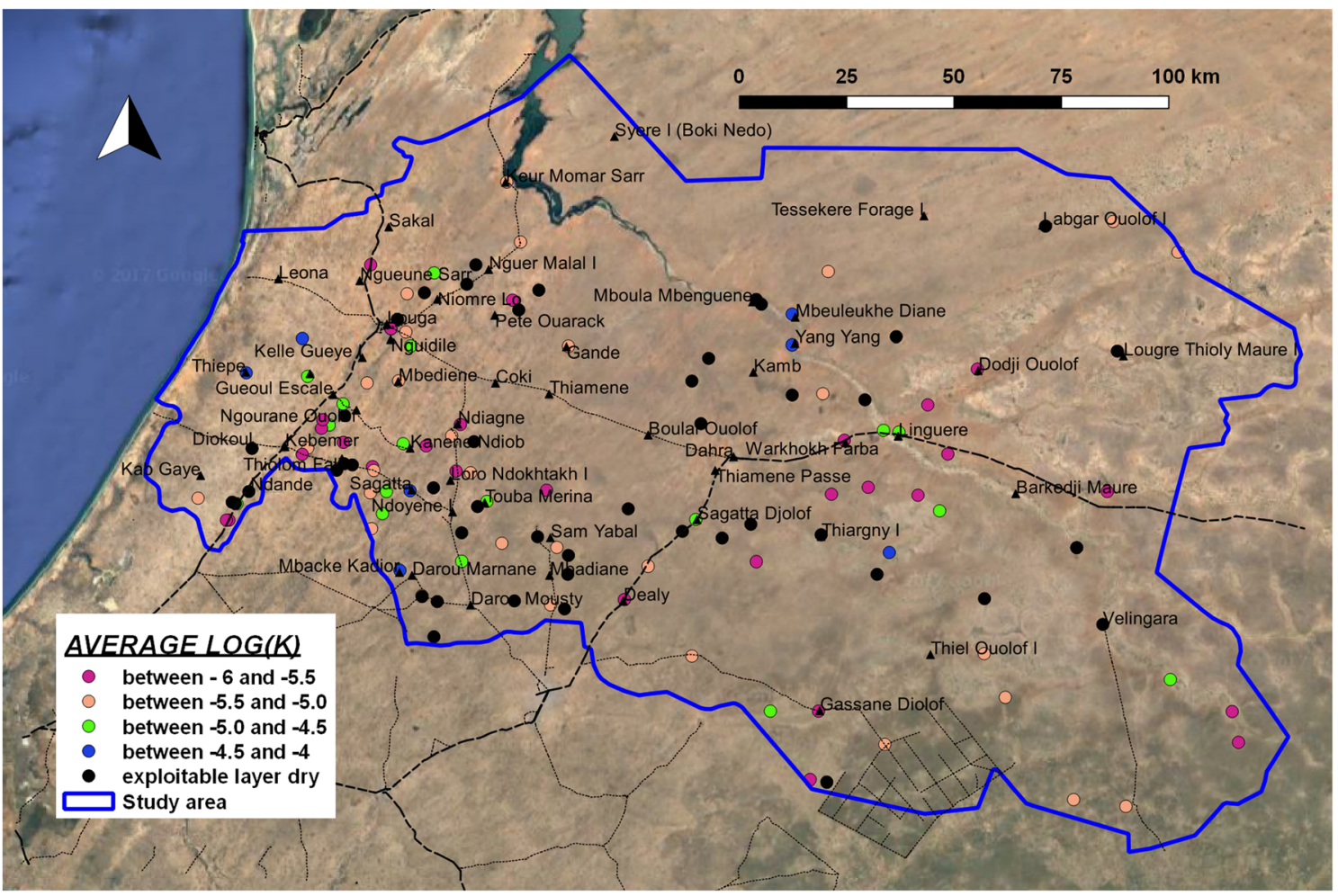

Fig. 9 Map of average $\log (K)$ in the saturated layer up to $50 \mathrm{~m}$ (hydraulic conductivity, $K$ in $\mathrm{m} / \mathrm{s}$ )

for steady flow. The drawdown is compared with the sitespecific condition of the expected maximum water column in the well (depending on the depth of groundwater) and seasonal fluctuations. In this way, it is possible to estimate the sustainability of a continuous and intense pumping. Considering the hydrogeological context of the study area,

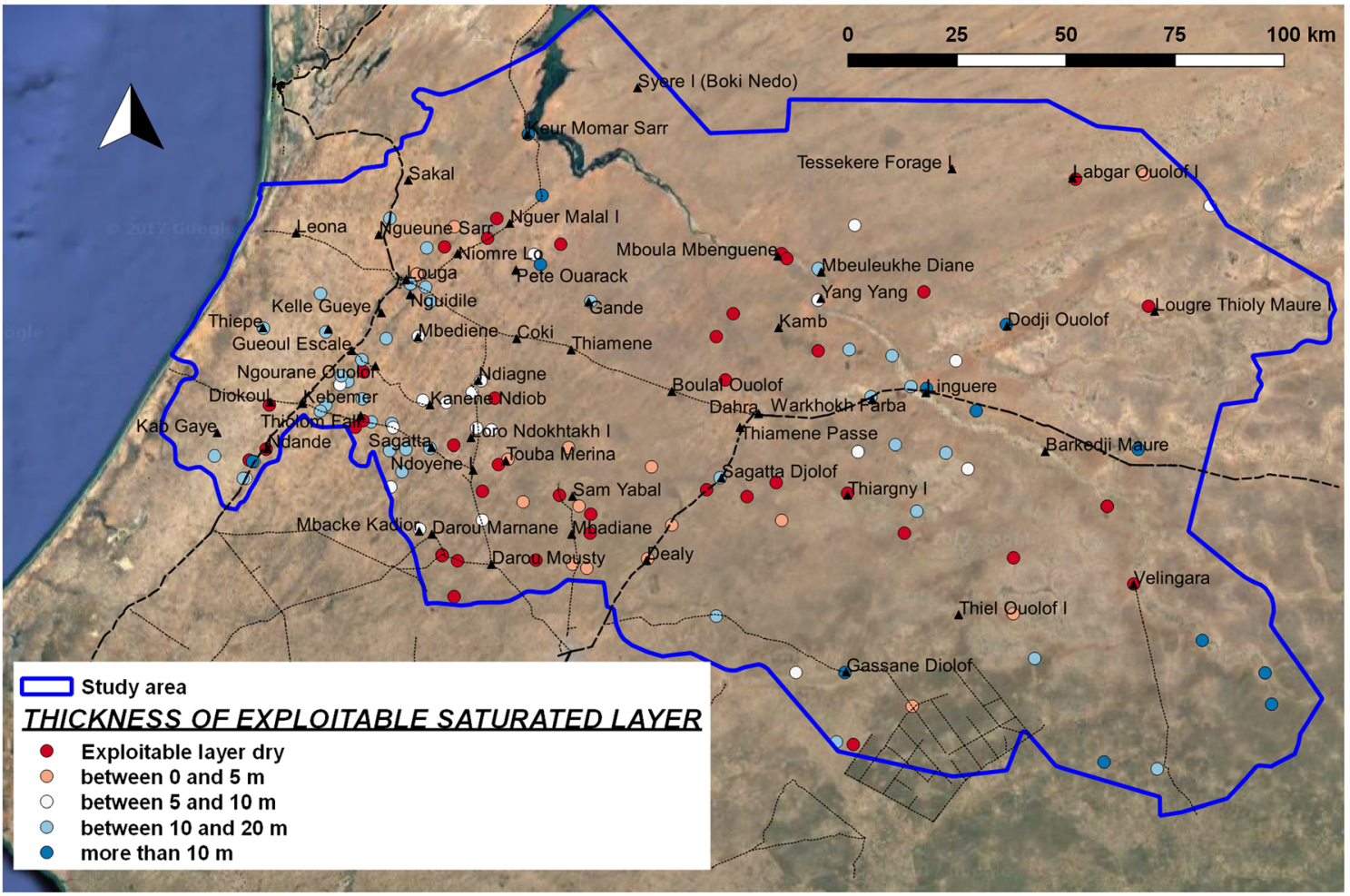

Fig. 10 Map of thickness of exploitable saturated layer, at borehole-log positions 
Table $8 T_{e x}$ limits of the five class of potential for manual drilling

\begin{tabular}{ll}
\hline Class of potential & Range of $T_{\mathrm{ex}}\left(\mathrm{m}^{2} / \mathrm{s}\right)$ \\
\hline NP: potential null & 0 \\
LP: low potential & Between 0 and $3.10 \times 10^{-5}$ \\
MP: moderate potential & Between $3.10 \times 10^{-5}$ and $5.10 \times 10^{-5}$ \\
GP: good potential & Between $5.10 \times 10^{-5}$ and $1.3 \times 10^{-3}$ \\
EP: excellent potential & More than $1.3 \times 10^{-3}$ \\
\hline
\end{tabular}

the threshold values of $T_{\text {ex }}$ shown in Table 8 were assumed. With this classification, it is possible to assess the distribution of potential in the whole study area (Fig. 11).

Suitability for manual drilling On the basis of the different hydrogeological parameters described previously, it has been possible to classify each borehole log in terms of feasibility and potential for manual drilling. The final class of suitability for manual drilling can be obtained from the combination of these two, as described in Table 4. The results of classification of suitability at borehole-log positions are shown in Fig. 12.

In those areas where manual drilling is considered feasible, one can observe a good potential in the coastal area and in the Ferlo valley (i.e. along the dry river between Mboula and Linguere, in the centre of the study area).
However, in this zone, the assessment of suitability can be not reliable, given the uncertainty about the real depth to water level in the shallow porous aquifer and the difference between direct field observations in largediameter wells and static water level data from deep boreholes in the national database, as previously explained. On the other hand, the area eastward from Kebemer (i.e. the region of Ndiob, Ndoyenne, Darou, in the SW sector of the study area) has several places with low potential, because of the double effect of the depth to water (therefore a small water column in the well, if maximum depth is $50 \mathrm{~m}$ ) and a higher percentage of fine materials (with a low value of $K$ ). In the case of drilling deeper than $50 \mathrm{~m}$, both estimated feasibility and potential would improve in this region, while in the NE sector the limitations imposed by the presence of shallow hard rock would not change the estimation of suitability. The estimation of feasibility depends on the limits of depth defined for manual drilling based on the experience of drillers. In this research, a maximum well depth of the wells at $50 \mathrm{~m}$ (and a maximum depth to exploitable water at $40 \mathrm{~m}$ ) was assumed. However, $20 \%$ of the data shows a water depth between 40 and $50 \mathrm{~m}$. The class of feasibility for these points would change in the case of increasing the maximum estimated depth of drilling by $10 \mathrm{~m}$ (this would be considered feasible).

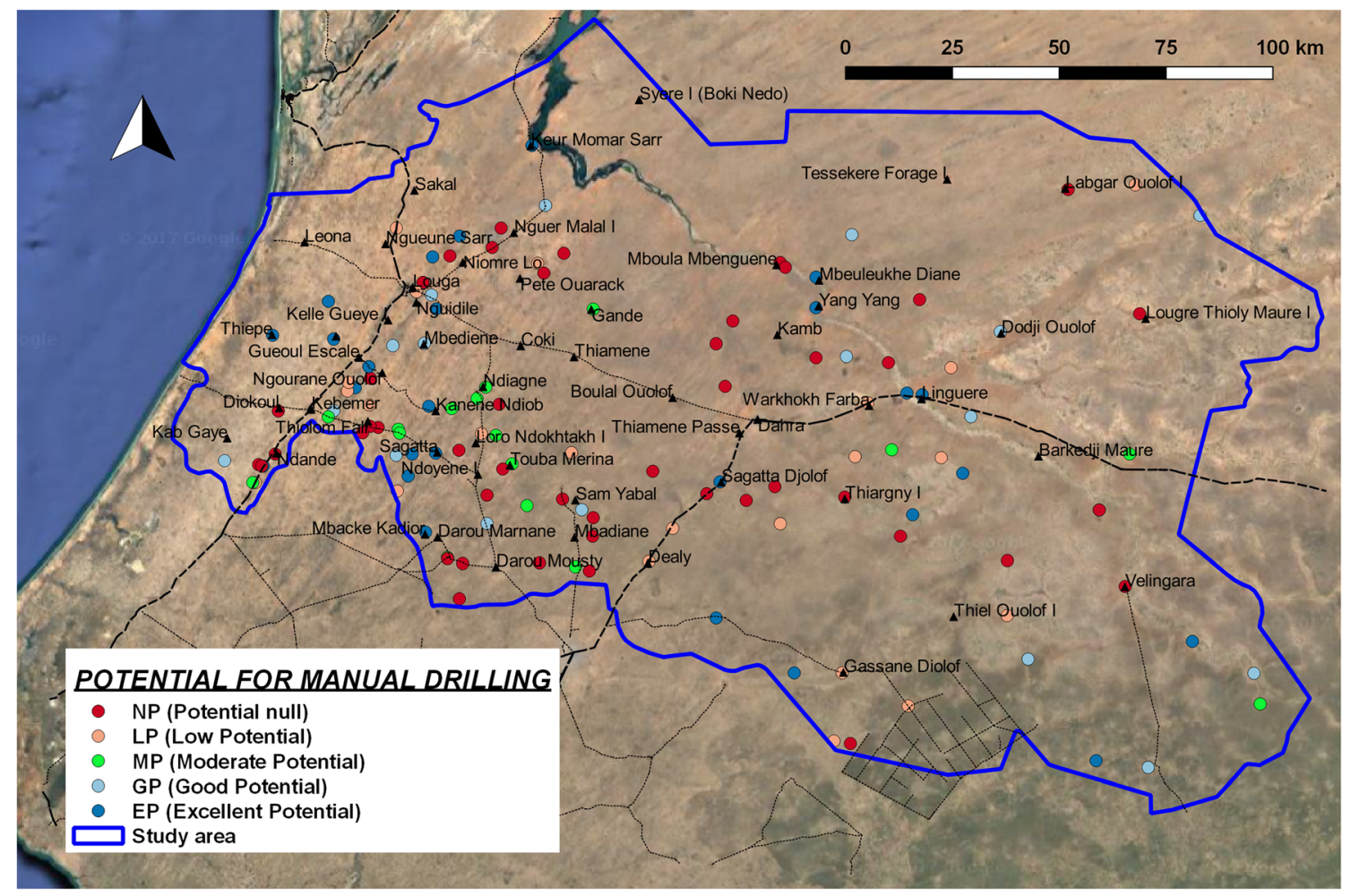

Fig. 11 Map of potential for manual drilling, based on $T_{\mathrm{ex}} . N P$ potential null, $L P$ low potential, $M P$ moderate potential, $G P$ good potential, $E P$ excellent potential 


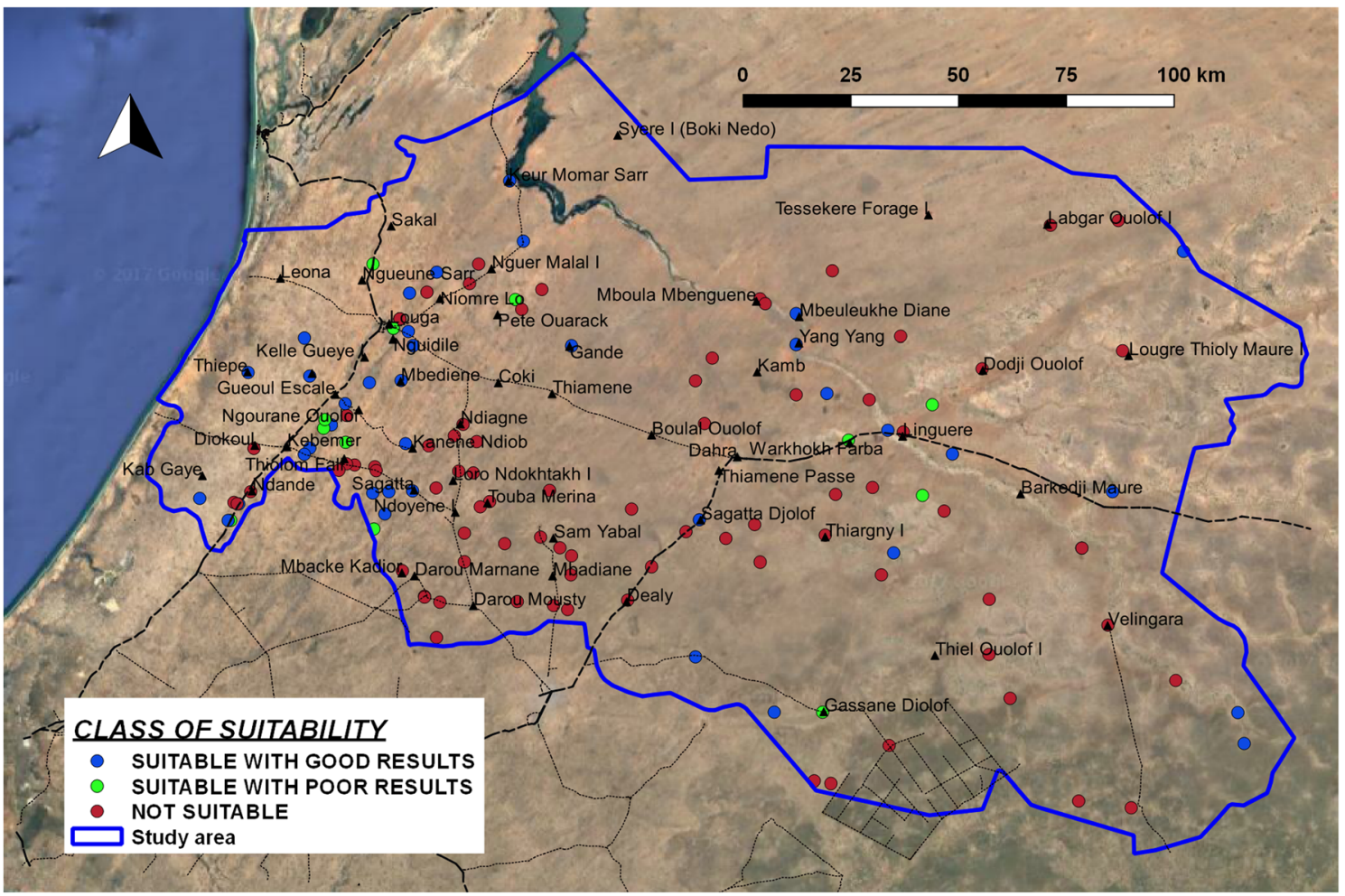

Fig. 12 Classification of suitability for manual drilling at borehole-log positions

\section{Conclusion}

This research allowed for the delineation of suitable zones to implement manual drilling in a region of northwestern Senegal, improving (i.e. increasing the scale of detail and the reliability of the interpretation by validation with real stratigraphic and hydraulic data) the previous map of suitable zones in this country (Kane et al. 2013).

During the research, a specific software (TANGAFRIC) and a structured method to carry out a semi-automated analysis of stratigraphic information through organization, codification and processing of existing borehole-log data have been developed. This activity was completed on a sample of 173 borehole logs (through manual input of stratigraphic codes carried out by technical staff in Senegal, followed by an automated procedure of data elaboration) in Louga region, but the process can be replicated with other data sets. In Senegal, the national database contains a detailed description of 1,419 stratigraphic logs scattered throughout the whole country, but many more are available in hard copy at the regional branches of the national water authority. The update of information concerning existing water points is still a difficult aspect; in recent years, increasing attention has been given to setting up an efficient system for water point mapping and monitoring. The lack of up-to-date information strongly limits the reliability of studies on the functionality of water supply and access to safe water, while it is less relevant for hydrogeological interpretation. The information stored in the national database is generally collected at the moment of construction of water points, but most of the hydrogeological data (especially stratigraphic description) does not change over time and the information is still correct.

In other countries in Africa, large databases of water points are stored by the national institutions, with limited capacity to analyse this information and exploit it to formulate hydrogeological interpretation. Tools and methods proposed in this research could provide a valid support to study not only the shallow hydrogeology but also deeper fractured formations, contributing to groundwater exploration and management.

In the next few years, manual drilling is expected to spread in several countries. Various international organizations and funding agencies are committed to supporting this processfor example, UNICEF and its partners PRACTICA Foundation and RWSN (Rural Water Supply Network) are running an important technical assistance program to create a highly professional manual drilling sector in many countries in Western and Central Africa (Central African Republic, Togo, Mauritania, Mali, Ivory Coast, Guinea, Niger, Nigeria, DRC) funded by DGIS (Directorate-General for International Cooperation of Dutch Government), DFID (Department of International Development of UK Government) and other donors. It would be important for scientific research to provide valid tools for effective planning and implementation of this 
process, which could produce a highly positive impact on access to safe water and the living conditions of the population.

Acknowledgements This study has been carried out in the framework of the project entitled "Use of remote sensing and terrain modelling to identify suitable zones for manual drilling in Africa and support low cost water supply", and is financed by NERC (National Environment Research Council, UK) in the framework of the program UPGRO (Unlocking the Potential of Groundwater for the Poor). The study has been carried out in two different study areas, in Senegal (whose results are presented in this report) and Guinea. This research has been possible thanks to the joint activities and positive collaboration of different partners from Italy, Senegal and Guinea (University Milano Bicocca, Université Cheik Anta Diop Dakar, University of Thies, SNAPE, Direction de l'Hydraulique of Louga region). We also want to acknowledge the support received from Richard Carter during the selection of the interpretation model for the pumping test, Kerstin Danert and Sean Furey (who went to all the effort of disseminating the results of this research), Alan McDonald and Yann Chemin during the preliminary review of this report.

Open Access This article is distributed under the terms of the Creative Commons Attribution 4.0 International License (http:// creativecommons.org/licenses/by/4.0/), which permits unrestricted use, distribution, and reproduction in any medium, provided you give appropriate credit to the original author(s) and the source, provide a link to the Creative Commons license, and indicate if changes were made.

\section{References}

ANTEA/BURGEAP (2007) Notice d'utilisation du logiciel PROGRES, version Guinée [PROGRES, Guinea version, user guide]. ANTEA, Heerenveen, The Netherlands; BURGEAP, Billancourt, France

Barker JA, Herbert R (1989) Nomograms for the analysis of recovery tests on large-diameter wells. Q J Eng Geol 22:151-158

Bonomi T (2009) Database development and 3D modeling of textural variations in heterogeneous, unconsolidated aquifer media: application to the Milan plain. Comput Geosci 35:134-145

Bonomi T, Fumagalli ML, Rotiroti M, Bellani A, Cavallin A (2014) Banca dati idrogeologica TANGRAM@: strumento per elaborazioni quantitative di dati per la valutazione delle acque sotterranee [The hydrogeological well database TANGRAM@: a tool for data processing to support groundwater assessment)]. Ital J Groundw 3(2/136):35-45

Bouwer H, Rice RC (1976) A slug test for determining hydraulic conductivity of unconfined aquifers with completely or partially penetrating well. Water Resour Res 12(4):423-428

Carter RC (2005) Human-powered drilling technologies. Cranfield University, Bedfordshire, UK

Cooper HH Jr, Bredehoeft JD, Papadopulos IS (1967) Response of a finite-diameter well to an instantaneous charge of water. Water Resour Res 3(1):263-269

Danert K (2009) Realizing the potential of hand-drilled wells for rural water supplies. Waterlines 28(2):108-129

Danert K (2015) Manual drilling compendium 2015. Rural Water Supply Network Publ. 2015-2, RWSN, St Gallen, Switzerland

Domenico PA, Schwartz W (1998) Physical and chemical hydrogeology, 2nd edn. Wiley, Chichester, UK

Fetter CW (1994) Applied hydrogeology. Prentice-Hall, New York
Forsyth AM, Ramudu E, Hindal EL, Lazarus DR (2010) A manual well drilling pilot project: implementing the water for all international method. Int J Serv Learn Eng 5(1):128-147

Freeze RA, Cherry JA (1979) Groundwater. Prentice Hall, Englewood Cliffs, NJ

Fussi F (2011) Mapping of suitable zones for manual drilling as a possible solution to increase access to drinking water in Africa, 6th Rural Water Supply Network Forum, Kampala, Uganda, 29 Nov-1 Dec 2011

Fussi F, Alvino R, Caruba M, Galimberti L, Marzan I, Tarrason y Cerda' D, Sabatini D (2013) Mapping of suitable zones for manual drilling as a possible solution to increase access to drinking water in Africa through integration of systematized GIS data and local knowledge. Geophys Res Abstr 15:2013-8937

Fussi F, Bonomi T, Fava F, Hamidou B, Khane CH, Faye G, Wade S, Colombo R (2014) Tangafric: a software for the estimation of textural and hydraulic properties in shallow aquifers from well logs in Senegal and Guinea. Geophys Res Abstr 16:12154-12155

Gaya S (2004) Rapport sur le test de miniforages et points filtrants en Casamance [Report of the test of small boreholes and drainage wells in Casamance] Technical report, UNICEF, New York

Gaya S, Fussi F, Van Der Wal A (2005) Assessment of the feasibility for manual drilling in Chad. Report phase I, UNICEF Chad, Oxfam GB, Practica Foundation, Arnhem, The Netherlands

Herbert R, Barker JA, Kitching R (1992) New approaches to pumping test interpretation for dug wells constructed on hard rock aquifers. In: Wright EP, Burgess WG (eds) Hydrogeology of crystalline basement aquifers in Africa. Geol Soc Spec Publ 66, 221 pp

Herbert R, Kitching R (1981) Determination of aquifer parameters from large-diameter dug well pumping tests. Ground Water 19(6):593599

Huisman Foundation (2014) Feasibility study for manual drilling in Alamata, Offla, Hawzien, and Klite Awlaelo areas, Tigray, northern Ethiopia. Huisman Foundation, Nijkerk, The Netherlands

Hvorslev MJ (1951) Time lag and soil permeability in ground-water observations. Waterways Experimental Station Bull 36, US Army Corps Engineers, Waterways Experimental Station, Vicksburg, MS

Kane CH, Fussi F, Diène M, Sarr D (2013) Feasibility study of boreholes hand drilling in Senegal: identification of potentially favorable areas. J Water Resour Protect 2013(5):1219-1226

MacDonald AM, Davies J (2000) A brief review of groundwater for rural water supply in Sub-Saharan Africa. Br Geol Surv Tech Rep WC/ 00/33, BGS, Keyworth, UK

MacDonald AM, Maurice L, Dobbs MR, Revees HJ, Auton CA (2012) Relating in situ hydraulic conductivity, particle size and relative density of superficial deposits in a heterogeneous catchment. J Hydrol 434-435:130-141

Mace RE (1999) Estimation of hydraulic conductivity in large-diameter, hand-dug wells using slug-test methods. J Hydrol 219:34-45

Neuzil CE (1994) How permeable are clays and shales? Water Resour Res 30(2):145-150

Papadopulos IS, Cooper HH Jr (1967) Drawdown in a well of large diameter. Water Resour Res 3:241-244

PEPAM (Programme d'Eau et d'Assainissement du Millenaire, République du Senegal) (2015) Data of Louga region at: http:// www.pepam.gouv.sn/acces.php?rubr=serv\&idreg=08. Accessed December 2015

République du Sénégal (2000) Système d'Information Géographique pour la gestion des ressources en eau [Geographic information system for the management of water ressources]. Ministère de 1'Hydraulique, Service de Gestion et de Planification des Ressources en Eau SGPRE, Dakar, Senegal

Rupp DE, Selker JS, Simůnek JA (2001) Modification to the Bouwer and Rice method of slug-test analysis for large-diameter, hand-dug wells. Ground Water 39(2):308-314 
Salama V (2008) Cartographie thématique des zones favorables aux techniques de captage et d'exhaure à faible coût [Thematic maps of suitable zones for low cost techniques of water extraction and drainage]. Practica Foundation, Arnhem, The Netherlands

Sanchez-Vila X, Girardi JP, Carrera J (1995) A synthesis of approaches to upscaling of hydraulic conductivities. Water Resour Res 31(4):867882

Sheperd RG (1989) Correlation of permeability and grain size. Ground Water 27:633-638

The Remote Sensing Institute South Dakota State University (1986) Mapping and remote sensing of the resources of the republic of Senegal: a study of the geology, hydrology, soils, vegetation and land use potential. Project USAID/RSI no. 685-0233.
National Plan for Land Use and Development. RSI of SDU, Brookings, SD

Thomas SA, McGwire KC, Lutz A, Kratt C, Trammell EJ, Thomas JM, McKay WA (2012) Geospatial and regression tree analysis to map groundwater depth for manual well drilling suitability in the Zinder region of Niger. J Hydrol 446:35-47

Uribe H, David E, Rupp DE, Arumí JL, Stewart RD, Selker JS (2014) Assessment of current and potential yield of hand-dug wells in a semi-arid zone in south-central Chile using an analytical methodology. Chilean J Agric Res 74(2):219-224

WHO/UNICEF (2014) Progress on drinking water and sanitation. Joint Monitoring Programme update. WHO, Geneva; UNICEF, New York 